\section{ELECTRICAL CLOCKS AND CLOCKWORK}

$T N$ the year I843 an electrical pendulum which forms I the basis of nearly all succeeding systems of electrical clockwork, was patented by the late Alexander Bain. (See Fig. . .)

The bob of the pendulum, $c$, consists of a coil of insulated wire. One end of the wire passes to the axis of the tumbler A $T$, the other, through the suspension spring $S$, to the plate $P_{1}, P_{1} P_{2}$ are plates, say of zinc and carbon, and are sunk in the earth to form the battery. From $P_{2}$ a wire $\mathrm{W}_{2}$ proceeds to $\mathrm{N}, \mathrm{MM}$ is a horse-shoe magnet. Whilst A T leans against $\mathrm{N}$, a current is passing, and $\mathrm{C}$ is

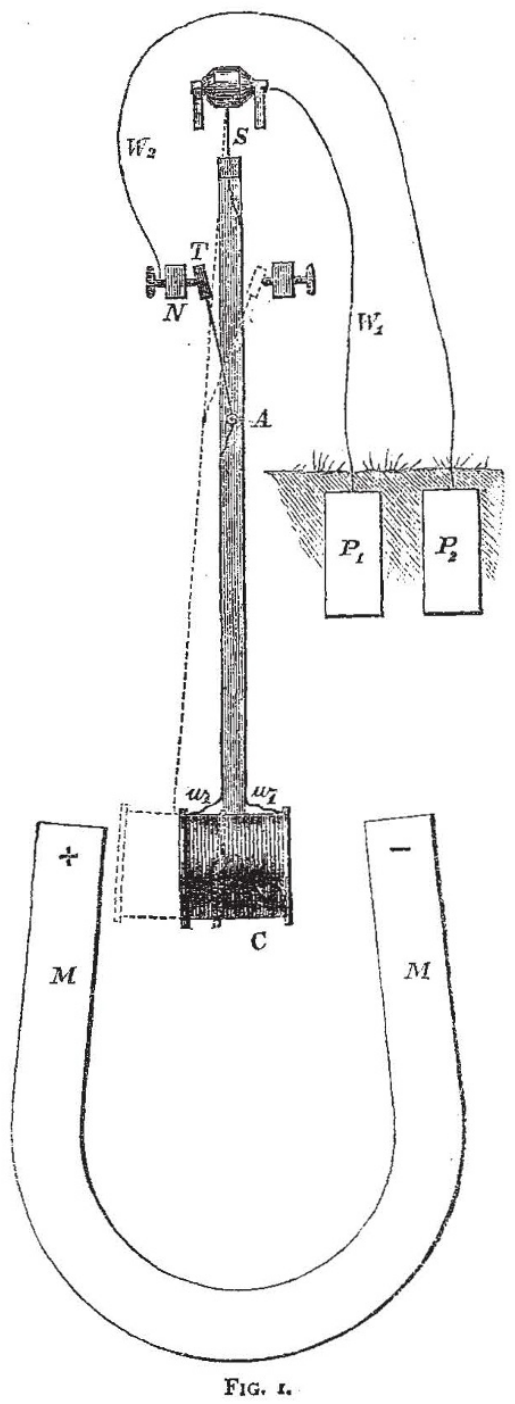

magnetic. $c$ has its - and + poles facing the + and poles of the horse-shoe magnet. Consequently the pendulum is driven to the left, but when it reaches a certain point, AT topples over, the current ceases, and the pendulum returns. The pendulum now proceeds on its swing to the right, but on approaching the limit of its oscillation, overturns AT again, the current is renewed, and the pendulum again propelled to the left. This action automatically repeats itself. Mr. Bain placed within the circuit of his pendulum any number of electrical dials. Fig. 2 shows the mechanism of these. $\mathrm{C}$ is a coil either in the line of $\mathrm{w}_{1}$ or $\mathrm{w}_{2}$. When a current passes $\mathrm{c}$ becomes magnetic, and oscillates between the magnets MM. At every swing of $\mathrm{C}$ a tooth, $\mathrm{T}_{1}$, of the wheel is gathered up by the detent DD. The click, $\mathrm{K} \mathrm{K}$, by holding a tooth, $T_{2}$, prevents the wheel returning whilst $D$ is passing to the right,

The impulse on Mr. Bain's pendulum varied with the power of his battery, a condition fatal to good timekeeping. In $1849 \mathrm{Mr}$. Shepherd patented a system in which the current was employed to lift a slight weight or

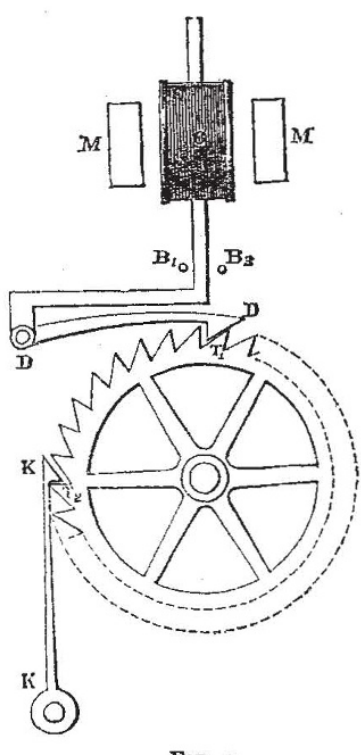

FrG. 2.

spring. The fall of this propelled his pendulum, and gave an impulse quite independent of any variation in the power of his battery. Fig. 3 shows one of his plans.

$\mathrm{PP}$ is the pendulum, $\mathrm{W}$ a weight, mounted on a lever WCA. WCA can move about a centre $\mathrm{C}$, and is at present prevented from turning by the catch SS. When PP swings to the right, the lower screw in P P passes under $\mathrm{E}$ (see side view $Z$ ) and frees WCA. WCA, under the weight of $w$, propels the pendulum to the left till stopped by a

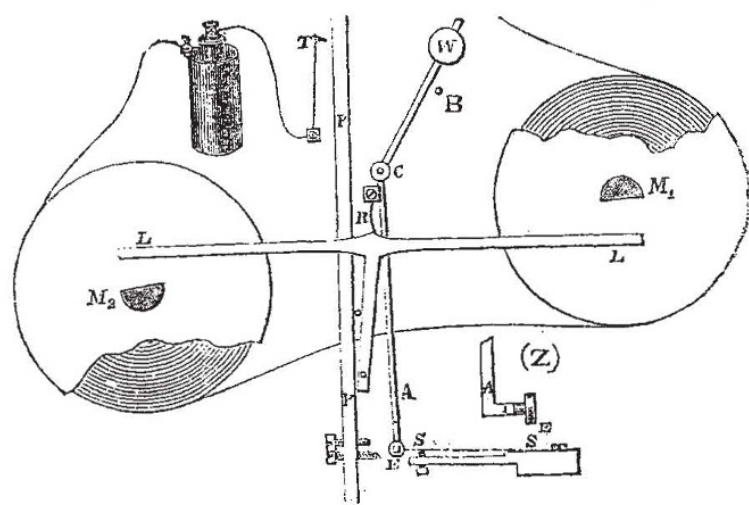

FIG. 3 .

banking B. PP moves on and makes contact with $T$, whereupon a current passes, $M_{1} M_{2}$ become magnetised, and attract $L L$, the vertical arm of which lifts $w a A$ over the catch SS again. When PP leaves $T$ the current ceases, and $L L$ is carried back to its old position by the action of the spring $R$.

Mr. Bain's and Mr. Shepherd's are the leading types of electrical clocks properly so called, that is to say, of clocks which keep themselves going by electricity. But it 
is scarcely worth while to use electricity when you can get gravity more cheaply. And do what you will, you can never absolutely rely on getting your current when you want it. For these reasons purely electrical clocks are very seldom used, it being found better to do whatever electrical work is required, by an ordinary clock with galvanic contact apparatus affixed. But though electrical clocks pure and simple have not made much progress, the system of controlling a quantity of indifferent clocks from one good one has. This principle was invented by Mr. Jones, of Chester, and Fig. 4 shows it.
(3) is the pendulum of the controlling clock, and (2) that of a controlled clock; ( $I$ ) is a side view of $(2) . \mathrm{C}$, the bob of (2) is a hollow coil of insulated wire, and swings over two magnets, $\mathrm{M}_{1} \mathrm{M}_{2}$, which have their similar poles facing each other. The ends of the wire forming $C$ are carried up the pendulum, pass respectively through $S_{a} S_{2}$ and terminate in $T_{x} T_{2^{*}} T_{x}$ is joined to $T$, which crowns the pendulum of the controlling clock, and $\mathrm{T}_{2}$ is in connection with both $N_{1} N_{2}$, the contact springs of the same. Both $\mathrm{N}_{1} \mathrm{~N}_{2}$ bave their respective batteries, $\mathrm{B}_{1} \mathrm{~B}_{2}$, but with opposite poles towards $\mathrm{J}$; so that if $\mathrm{C}$ is magnetised in one

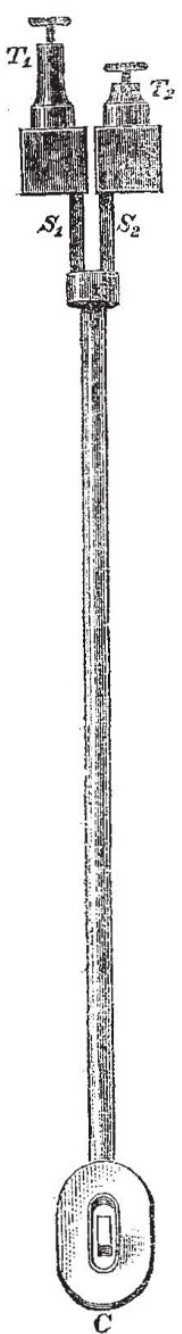

(1)

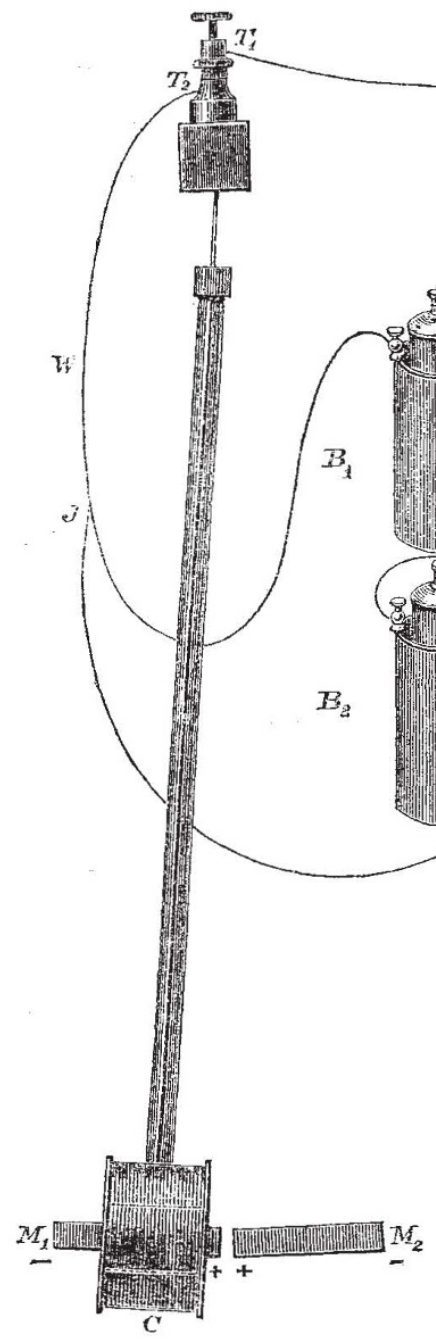

(2)

Fig. 4.

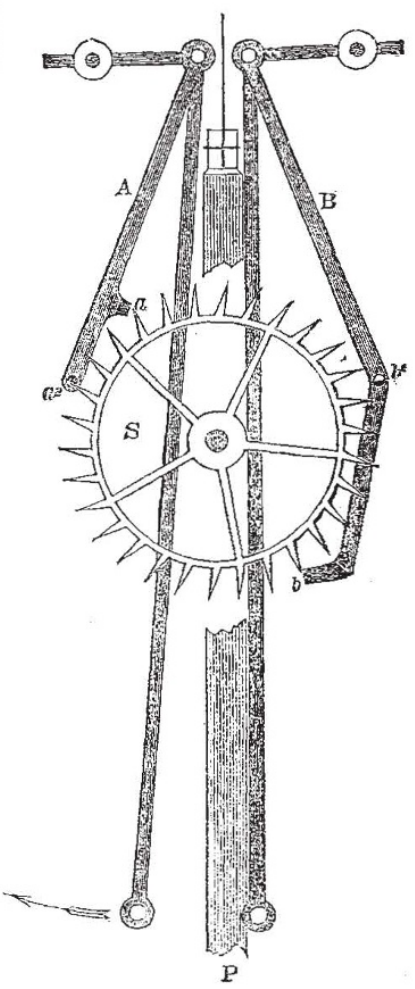

FIG. 5. direction by one, it will be magnetised in the opposite by the other.

Suppose (2) has a tendency to lag as compared with (3). When (3) approaches the extremity of its swing, G meets $\mathrm{N}_{2}$, a current passes, $\mathrm{C}$ is magnetised and is pulled on smartly. When $\mathrm{G}$ leaves $\mathrm{N}_{1}$, the current ceases, G goes to meet $\mathrm{N}_{2}$, then $\mathrm{C}$, which is now over $\mathrm{M}_{2}$, is again magnetised, but in the reverse direction. $\mathrm{M}_{2}$ being also reversed as regards $M_{1}$, $C$, if behind, is pulled on again. Should (2) be in front of (3) its motion would be checked. A great many clocks can by this method be kept swinging in unison together.

$\mathrm{Mr}$. Ritchie, of 25, Leith Street, Edinburgh, has patented an ingenious modification of the above. He places in the circuit of his controlling clock not other clocks, but pendulums. These he drives in just the same way as Mr. Jones controls his, and each pendulum works a train of wheels which move hands. Mr. Ritchie's are really electrical dials, but they have this great advantage, that should the current fail, as currents are apt to occasionally, the momentum of the pendulums is sufficient to keep the dials moving for a short time independently of it. The method by which the pendulums drive the wheel work is interesting (see Fig. 5).

$A$ and $B$, the pallets, swing loose. $S$, the escape wheel, is now being held against $a_{2}$, a stop on $\mathrm{A}$, by the weight of 
$B$, which is pressing the tooth $b$. B has been deposited on $b$ by the pendulum $P$, which is swinging to the left. Presently the pendulum lifts the vertical arm of $\mathrm{A}$, and unlocks the wheel. The wheel moves on, but B falls, and the stop $b_{2}$ on $B$ catches the tooth which is just above it. The pendulum continues its swing, and on returning, deposits $\mathrm{A}$ on the next succeeding tooth to $a$. It then proceeds to $\mathrm{B}$, and continues the performance as before.

It is desirable that you should know that all your controlled or driven clocks are performing properly. In the circuit, alongside the standard clock, a galvanometer is

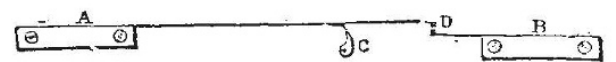

Fig. 6.

placed, and each of the controlled or driven clocks is fitted with the following mechanism (see Fig. 6).

$A D, D B$ are two springs through which the current passes. $\mathrm{C}$ is a lifter upon the axis of the escape wheel of one of the controlled or driven clocks. Every minute c comes round and breaks the circuit for one second, and anybody standing at the controlling clock, knows when this bappens by the needle of the galvanometer remaining stationary. We arrange, for instance, that clocks $A, B, C, D$ shall cut out respectively the $3 \mathrm{rd}$, 9 th, $\mathrm{I} 5 \mathrm{th}$, and 4 oth seconds, and if these seconds are regularly cut out, we know that our controlled clocks are running with the standard.

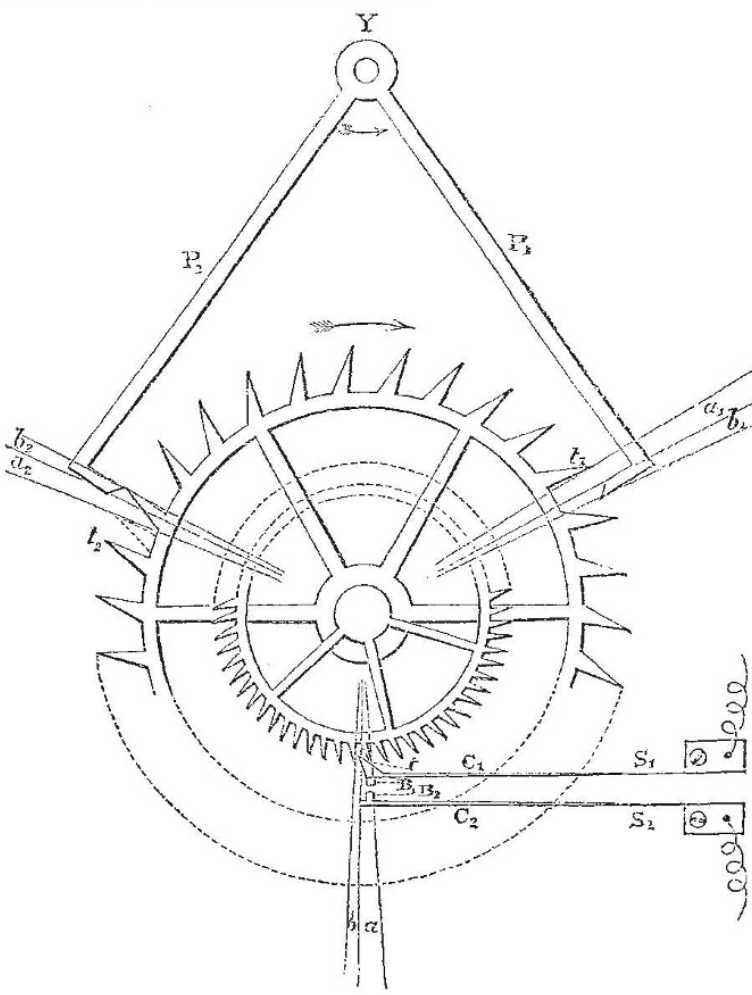

FIG. 7.

It is a matter of importance that the system of making electrical contact shall disturb the pendulum as slightly as possible. The method described above (by the two springs $N_{1} N_{2}$ ) would scarcely suffice, when the most accurate timekeeping was required. The standard sidereal clock at Greenwich has a jewelled pin in the crutch rod which in passing zero presses two weak springs together. A better plan (Mr. Hartnup we are informed had also previously used it) seems one which has just been constructed by Messrs. Dent for some other work. In this it would appear that the resistance of the contact springs cannot affect the penduium at all; because the springs are lifted during the drop of the escape wheel from one pallet to the other (see Fig. 7).

A tooth has just passed from the impulse face of the

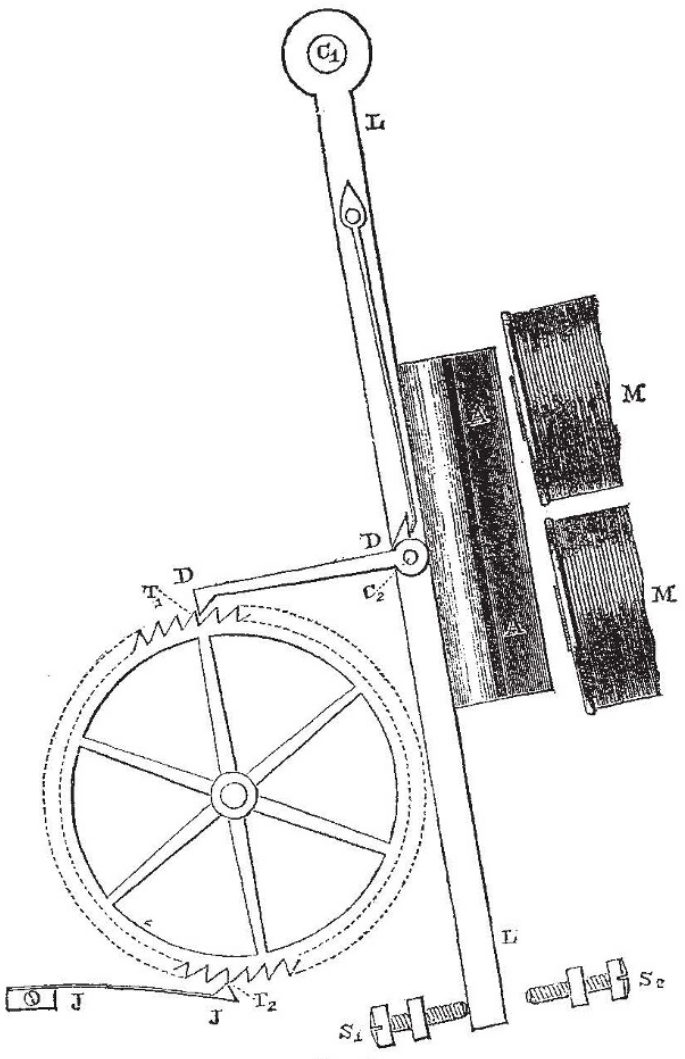

Fig, 8.

pallet $P_{2} ; t_{1}$ now falls through the angle $a_{1}$ on to the dead face of the pallet $P_{1}$. During this interval the tooth $t$ of the smaller wheel mounted on the same axis as the escape

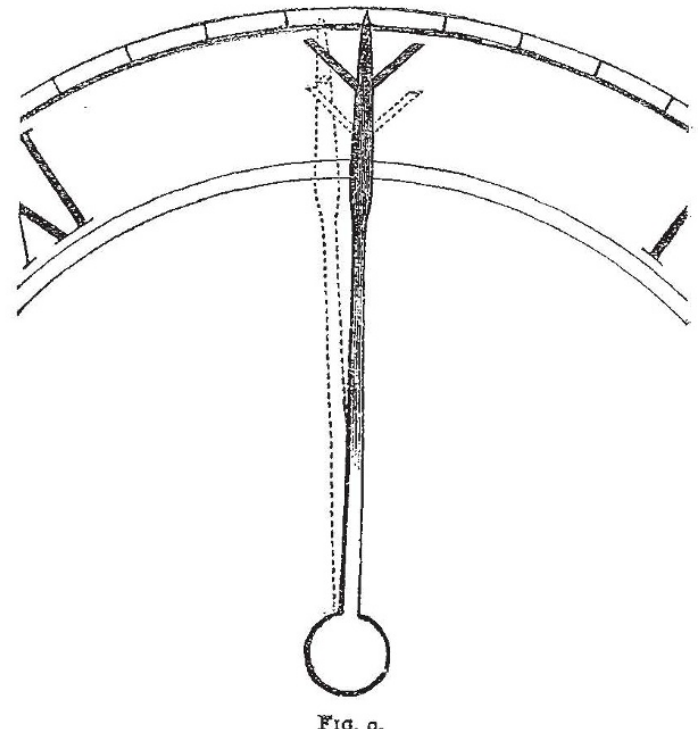

wheel lifts the contact spring $C_{1} S_{1}$ against the contact spring $c_{2} s_{2}$, and the current passes. It will be seen that when the tooth $t_{1}$ goes on to give impulse to the pallet 
$P_{1}$ through the angle $b_{1}$, the tooth $t$ has allowed the springs to drop, and that it travels through its corresponding angle $b$ perfectly undisturbed. The motion of the tooth $t_{2}$ can easily be traced from the drawing. Careful workmanship is required to carry out this method properly, as the angles $a, a_{1}, a_{2}$ ought to be made much smaller than in the drawing.

Fig. 8 shows some electrical dial work.

$\mathrm{MM}$ are coils, $\mathrm{AA}$ is an armature, $\mathrm{L} \mathrm{L}$ a lever turning about C. DD is mounted on $L L$ and kept in position by a spring. $J \mathrm{~J}$ is a jumper. As soon as a current ceases, $L \mathrm{~L}$, which has been attracted by $\mathrm{MM}$, falls, and $\mathrm{DD}$ drives forward a tooth, $T_{1}$. When D D reaches the limit of its thrust, the point of $\mathrm{J} J$ just gets round the corner of $\mathrm{T}_{2}$, and drives on $\mathrm{T}_{2}$, makes it jump a little further. The jumper seems a better arrangement than the usual ratchet.

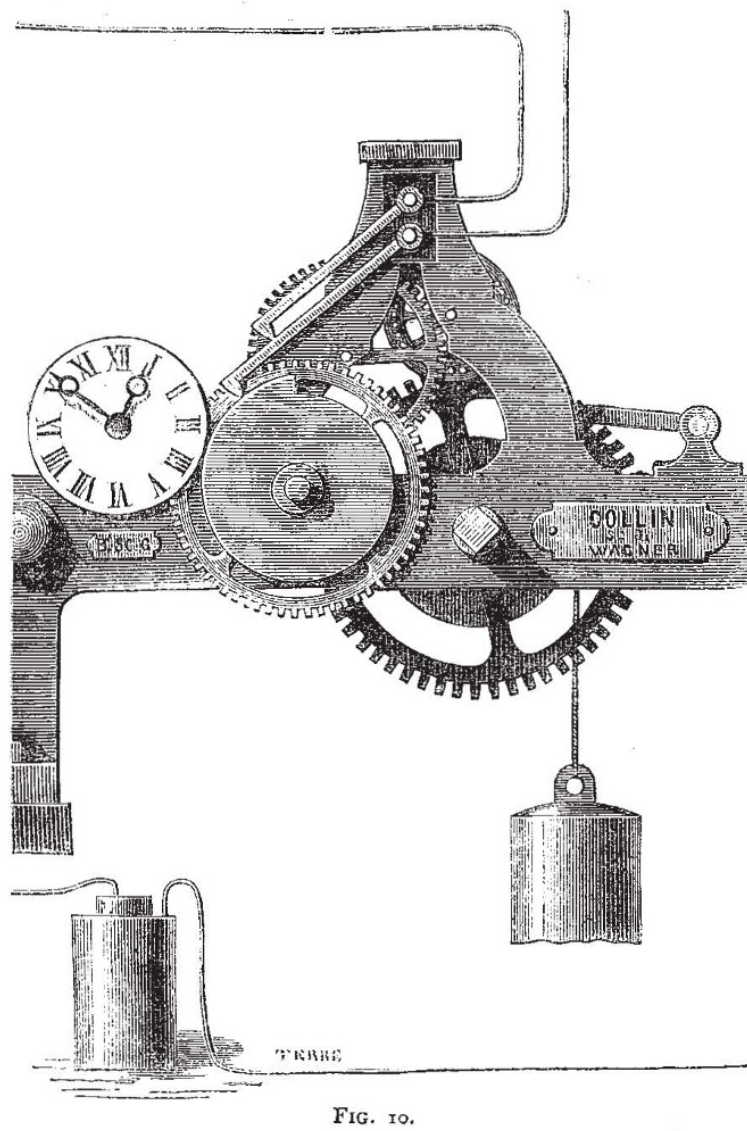

It has become popular of late to set the hands of indifferent clocks by electricity. This plan was proposed by Mr. Bain as far back as 1843, and his methor of accomplishing it was as follows (see Fig. 9). Behind the minute hand at I 2 o'clock is placed a V, and in the minute hand is a pin. Every hour a current from the standard clock raises the V. Should the hand be fast or slow it is immediately forced to the hour, for the pin is bound to find its position at the bottom of the V. A plan similar in operation has recently been patented by Messrs. Barraud and Lund. It is fully described in NATURE, vol. xix. p. 55.

Another method of correcting clocks was invented by M. Collin, Chevalier of the Legion of Honour, and has been largely made use of by him. Fig. Io shows his standard clock, and Fig. I I the clock to be corrected; the latter is regulated to gain a second or two per hour. A few minutes before each hour the lower of the two detents in Fig. Io is lifted against the upper, and a current passes. As regards the clock, Fig. I I, the current avoids

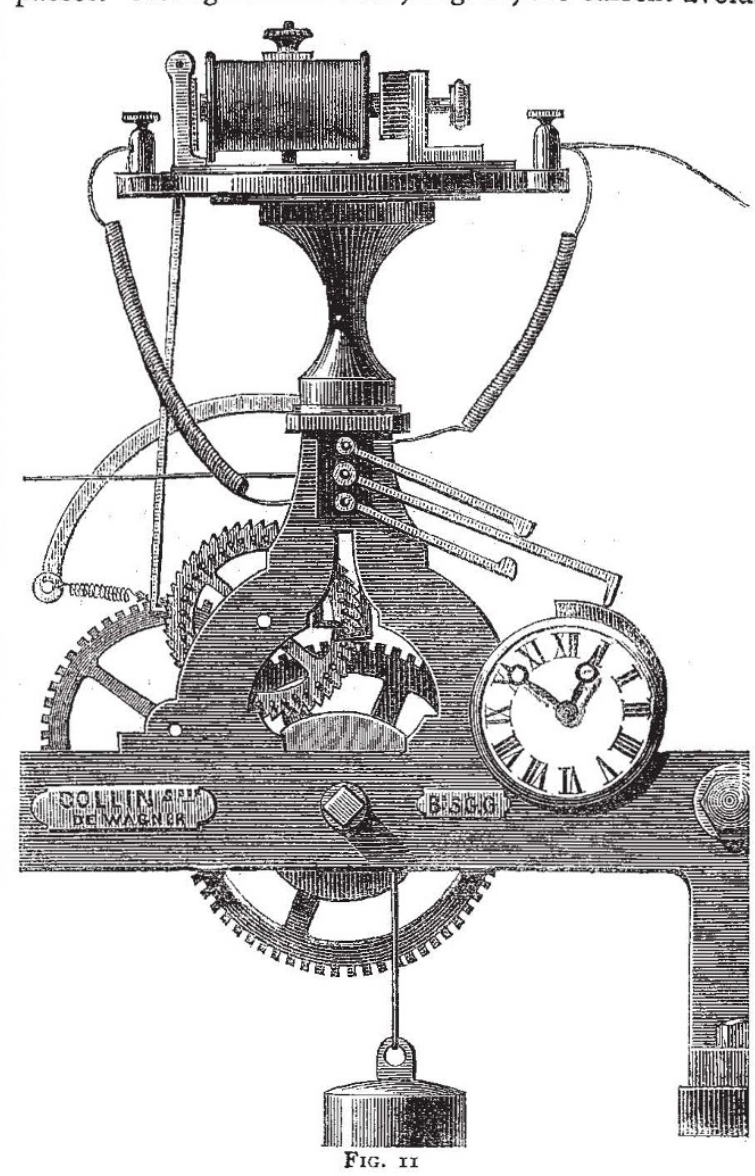

for the present the coil mounted on the top of it. When

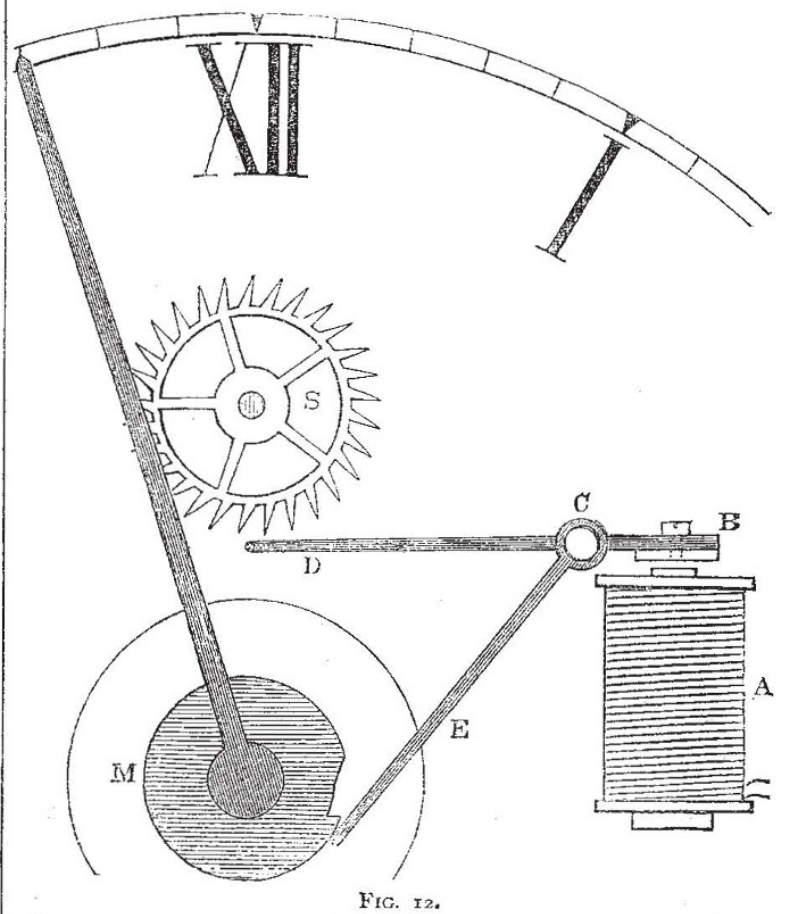

the clock, Fig. II, reaches the hour, it allows the long 
detent shown in the drawing to fall; this closes the circuit, and a hook attracted by the coil, catches a tooth cut in the escape-wheel, and holds it till the standard clock reaches the hour. At the hour the standard clock, Fig. 10, allows the lower detent to fall, and so breaks the circuit. Consequently the clock, Fig. I , starts off side by side with the standard.

Mr. Ritchie, to whom we have referred before, has also devised a plan for correcting clocks by hourly currents. His clock, to be corrected in like manner, gains some second or two per hour. Fifteen seconds before each hour the lever D B (see Fig. I2) is attracted by the electromagnet $A$, and a pin in the arm $D$ would thereupon enter and catch a tooth of the escape-wheel, did the disc $M$ allow the other arm of the lever $\mathrm{E}$ to move. When the hand reaches the hour, $E$ falls, then $D$ catches $S$ and holds it till the cessation of the current at the sixtieth second of the governing clock.

Generally the use of a Iong telegraphic wire can only be commanded for a few minutes daily. Fig. 13 shows a very suitable arrangement to be adopted when this is the case. By means of the 24 -hour disc the line wire is held in communication with the telegraph office until a

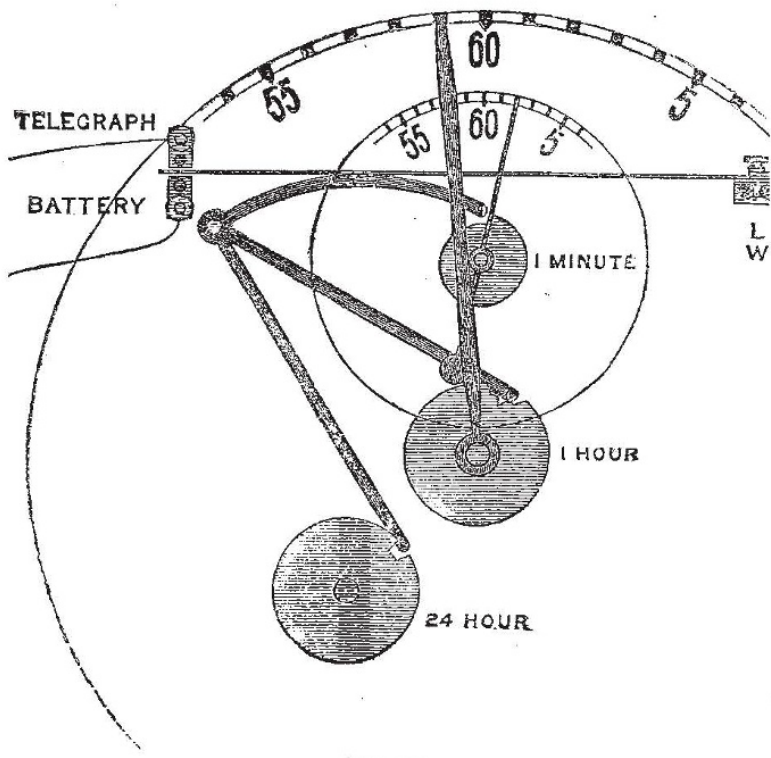

FIG, 13.

few minutes before the clock current is going to be despatched. The notch in the 24 -hour disc will at last allow the system of levers to fall, but then the I-hour disc supports them until about one minute before the clock current is coming; so that, till then, the line is being used for messages. The line wire has not been allowed to fall into circuit with the battery wire; this is still prevented by the I-minute disc. At the sixtieth second precisely the 1 -minute disc allows the line wire to join the battery wire, and out goes the clock current. Some seconds afterwards the I-hour disc lifts the line wire back into communication with the telegraph office, where it stays for another twenty-four hours.

The Great Westminster Clock reports its own time to Greenwich by the following arrangement:--Some minutes before a signal is due, a lever is lifted by a slow whecl into such a position that a pin in the next wheel at its coming rotation will catch it. The second wheel lifts it so much further that a pin in the escape wheel reaches it, presses two slight springs together, and sends off the signal.

A method of driving an electric dial was contrived by the late E. J. Dent. A powerful magnet was lifted through a coil of insulated wire by a strong tower clock movement. Every half minute the magnet was dropped a current was generated in the coil, which proceeded to the dial and moved the hands. A plan on the same principle has lately been used for clriving a number of small dials. A pendulum having a hollow coil of insulated wire for a bob, is by a heavy weight kept oscillating over a system of magnets. Currents are generated in the coil which proceed to the dials and work them.

Only the principal inventions in electrical clocks and clock-work have been indicated in this article. Since the year I 843 upwards of thirty patents have been applied for for improvements in such clocks and clockwork. It will be seen from this the subject, though not a wide one, is extensive.

Mr. Ritchie kindly lent diagrams $5,6,9,12$, and 13 to illustrate his plans, and M. Collin Io and $I x$. Figs. $I$ and 3 have been arranged to exhibit their working with clearness.

HENRY DENT GARDNER

\section{TAUNTON COLLEGE SCHOOL}

NE are sorry to chronicle the extinction of a school once watched with interest by all supporters of scientific education. The company which formed it is insolvent; the school buildings with the fine library and all the collections and apparatus which the late headmaster amassed will be sold for the benefit of the creditors; the shareholders will lose their money; and the town will fall back for its higher education on the old, dilapidated, unhealthy grammar school.

The directors of the company, who constituted the council of the school, have performed no ordinary feat. Four years ago the school was nearly full, its annual profits considerable, its distinctions, and consequent reputation, unprecedented in so young an institution; public lectures in literature and science attracted to its hall large classes from the town and neighbourbood; and its systematic teaching of science to all its pupils was studied and imitated by many other schools. The council exhibited sudden activity; they starved the teachingstaff, interfered with the discipline and management, thwarted, harassed, humiliated the head-master. Warnings from parents and old pupils fell upon them unheeded. The last term of 1877 saw two open scholarships at Oxford, two places in Cooper's Hill, and a host of minor honours gained by the boys; but it saw also the head. master bullied into resignation, and all but a handful of the pupils withdrawn by their indignant friends. The fate of the school was clear to all except the council; it has lingered on only to add to the liabilities of the share holders, who have now met to learn from their directors the history of a great scheme blighted, of insolvency far beyond the value of the mortgaged property, of their ancient school relapsed into the feeble, obsolete, pro. vincial position from which $\mathrm{Mr}$. Tuckwell rescued it.

\section{ON SUPERSATURATION}

A

SOLUTION is a case of adhesion overcoming cohesion; and when these two forces are in equilibrium the solution is said to be saturated.

In general the adhesive force is diminished by lowering the temperature, and a portion of the solid, a salt, for example, is thrown down; but it is increased by raising the temperature, so that the liquid can take up an additional portion of the solid.

In the case of a large number of salts, but for the most part those that are hydrated, a solution saturated at a given high temperature can be reduced to a lower one without depositing any salt, in which case the solution is said to be supersaturated, because it contains more salt than it can take up at the reduced temperature.

For example, 1oo parts of water at $194^{\circ} \mathrm{F}$. will 